Review

\title{
Review of procedures involving separation and preconcentration for the determination of cadmium using spectrometric techniques
}

\author{
Sérgio L.C. Ferreira ${ }^{a}{ }^{*}$, Jailson B. de Andrade ${ }^{a}$, Maria das Graças A. Korn ${ }^{a}$, \\ Madson de G. Pereira ${ }^{b}$, Valfredo A. Lemos ${ }^{c}$, Walter N.L. dos Santos ${ }^{b}$, \\ Frederico de Medeiros Rodrigues ${ }^{a, d}$, Anderson S. Souza ${ }^{a, e}$, \\ Hadla S. Ferreira ${ }^{a}$, Erik G.P. da Silva ${ }^{a}$ \\ a Instituto de Química, Campus Universitário Ondina, Universidade Federal da Bahia, Salvador, Bahia 40170-290, Brazil \\ ${ }^{\mathrm{b}}$ Departamento de Ciências Exatas e da Terra Campus 1-Cabula, Universidade do Estado da Bahia, Salvador, Bahia 41195-001, Brazil \\ ${ }^{\mathrm{c}}$ Laboratório de Química Analítica, Campus de Jequié, Universidade Estadual do Sudoeste da Bahia, Jequié, Bahia 45200-190, Brazil \\ d Empresa Baiana de Desenvolvimento Agrícola S.A., Avenida Dorival Caymmi 15649, Itapoan, Salvador, Bahia 41635-150, Brazil \\ e Instituto Multidisciplinar em Saúde, Campus AnísioTeixeira, Universidade Federal da Bahia, Vitória da Conquista, Bahia 45055-090, Brazil
}

Received 15 January 2007; received in revised form 25 March 2007; accepted 26 March 2007

Available online 30 March 2007

\begin{abstract}
Spectrometric techniques for the analysis of trace cadmium have developed rapidly due to the increasing need for accurate measurements at extremely low levels of this element in diverse matrices. This review covers separation and preconcentration procedures, such as electrochemical deposition, precipitation, coprecipitation, solid phase extraction, liquid-liquid extraction (LLE) and cloud point extraction (CPE), and consider the features of the their application with several spectrometric techniques.
\end{abstract}

(C) 2007 Elsevier B.V. All rights reserved.

Keywords: Cadmium; Spectrometric techniques; Preconcentration; Separation

\section{Contents}

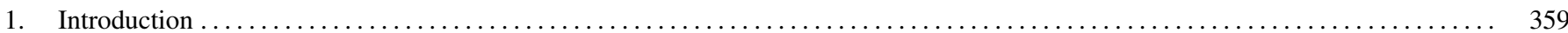

1.1. Cadmium determinations by using atomic spectrometry techniques and preconcentration procedures $\ldots \ldots \ldots \ldots \ldots \ldots \ldots$

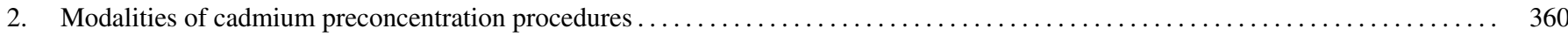

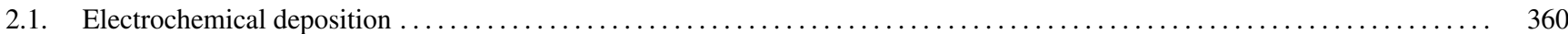

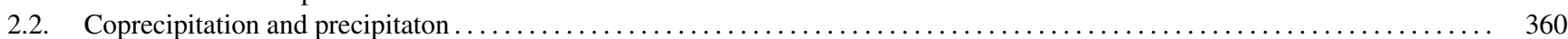

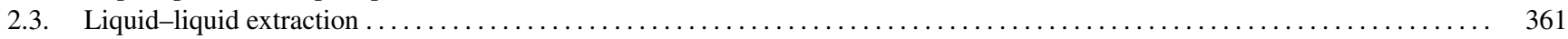

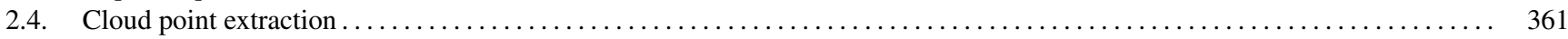

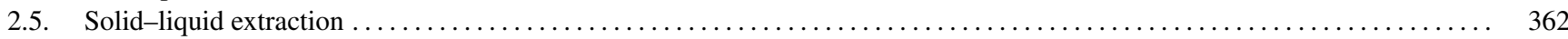

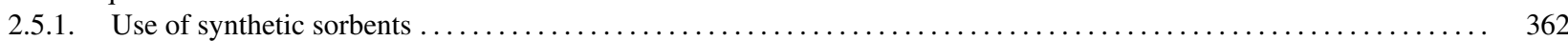

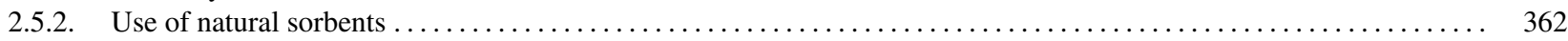

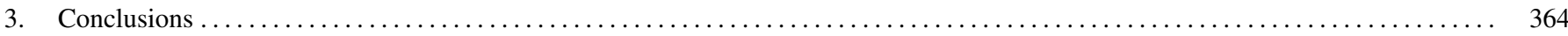

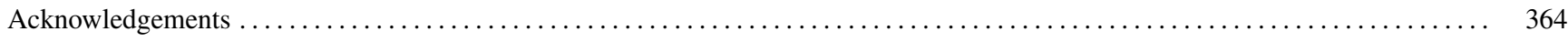

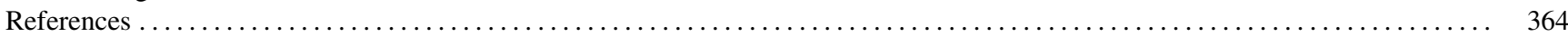

\footnotetext{
* Corresponding author.

E-mail address: slcf@ufba.br (S.L.C. Ferreira).
} 


\section{Introduction}

The word cadmium derives from the Latin cadmia (now known as "calamine") and the Greek kadmeia. Cadmuim, a silvery grey metallic, is a naturally occurring metallic element $\left(0.16 \mathrm{mg} \mathrm{kg}^{-1}\right.$ in the earth's crust) and it is found in mineral structures combined with other elements such as oxygen, chlorine or sulphur. All soils and rocks, including coal and mineral fertilizers, contain cadmium at variable concentration levels [1-5].

Cadmium was discovered in 1817 , in Germany, by F. Stromeyer and cadmium sulfide (CdS) was used as a paint pigment as early as 1850, and appeared prominently in the yellow colors of the Vincent Van Gogh paints. Their industrial applications were developed in the late 19th and early 20th century. The main uses of cadmium is in nickel-cadmium batteries, invented by Thomas A. Edson in the early part of the 20th century, and in cadmium coatings for the corrosion protection of steel $[1,6]$.

Our environment contains countless sources of cadmium and, in the modern world, this element is ubiquitous in food, water and air. The most human cadmium exposure comes from the tobacco smoke and from ingestion of food, which most of that arises from the uptake of cadmium by plants from fertilizers, sewage sludge, manure and atmospheric deposition [5,7]. Cadmium is not regarded as essential to human life, otherwise, cadmium is now known to be extremely toxic $[2,8]$ and accumulates in humans mainly in the kidneys for a relatively long time, from 20 to 30 years [1]. Prolonged intake, even of very small amounts, leads to severe dysfunction of the kidneys. At high doses it is also known to produce health effects on the respiratory system and has been associated with bone disease. More recently, the possible role of cadmium in human carcinogenesis has been also studied. In human body, cadmium acts by binding to the -SH group of cysteine residues in proteins and so inhibits - $\mathrm{SH}$ enzymes. It can also inhibit the action of the zinc enzymes by displacing the zinc $[5,6]$.

Cadmium will invariably be present in our society, either in useful products or in controlled wastes. Nowadays, its heath effects are well understood and well regulated, so that there is no need to restrict or ban cadmium products. On the other hand, the environmental safety will only be attained after the establishment of analytical protocols devoted to cadmium determination in different matrices (soil, water, vegetation, air, food, beverages and biological fluids). These aspects are discussed in the next sections.

\subsection{Cadmium determinations by using atomic spectrometry techniques and preconcentration procedures}

The following principles are general for all metallic ions and are also applicable to specific case of the cadmium.

Atomic spectrometry techniques - mainly flame atomic absorption spectrometry (FAAS), graphite furnace atomic absorption spectrometry (GFAAS), inductively coupled plasma optical emission spectrometry (ICP-OES) and inductively coupled plasma mass spectrometry (ICP-MS) - are extensively employed in the cadmium determination and, for this reason; the discussions established in this review are based on the applications of them. Eventually, techniques used in smaller frequency, as thermospray flame furnace atomic absorption spectrometry (TS-FF-AAS), hydride generation atomic absorption spectrometry (HG-AAS) and hydride generation atomic fluorescence spectrometry (HG-AFS) are cited in the text.

From the analytical tools above listed, FAAS presents low costs, operational facility and high sample throughput. The determination of cadmium by flame atomic spectrometry is free of interference and this can be easily atomized in air-acetylene flame. In the resonance line $228 \mathrm{~nm}$, the characteristic concentration is $0.02 \mathrm{mg} \mathrm{L}^{-1}$. The analytical line at $326.1 \mathrm{~nm}$ is suitable for determining higher $\mathrm{Cd}$ concentrations and the characteristic concentration is about $6 \mathrm{mg} \mathrm{L}^{-1}$, so that excessive dilution can be avoided [9].

Cadmium can be determined by CV AAS where atomic $\mathrm{Cd}$ vapor is measured by AAS in an unheated quartz cell. LOD of $80 \mathrm{ng} \mathrm{L}^{-1}$ was obtained which can be further improved by working at low temperature. The sensitivity can be increased collecting the atomic $\mathrm{Cd}$ vapor in a graphite tube pre-treated with palladium at $150{ }^{\circ} \mathrm{C}$ and then reatomizing at $1600^{\circ} \mathrm{C}$ [1]. Cold vapor generation coupled to atomic absorption spectrometry with flow injection (FI-CV AAS) was evaluated as a rapid and simple method for the determination of cadmium [10].

The determination of cadmium by ETAAS was, for a long period, difficulty because the cadmium is an element with high volatility [11]. Several alternatives can be used to improve these conditions by using fast heating rate; STPF conditions; Zeemaneffect to eliminate spectral interferences; $\mathrm{Pd}-\mathrm{Mg}$ as a modifier, possibly with the addition of ammonium nitrate. The maximum pyrolysis temperature is about $800^{\circ} \mathrm{C}$. In a longitudinally-heated atomizer at an atomization temperature of $1500-1700^{\circ} \mathrm{C}$ the characteristic mass is about $0.4 \mathrm{pg}$. If the attainable sensitivity is too high at the primary resonance line, as is often the case for direct solids analysis, the only usable alternate line is at $326.1 \mathrm{~nm}$ with a lower sensitivity by a factor of about 300 [9]. The use of modifier stabilizes cadmium allowing for its determination without causing matrix effects. The $\mathrm{Pd}-\mathrm{Mg}$ with the addition of ammonium nitrate as a modifier is the one more commonly used, however permanent chemical modifier as $\mathrm{W}+\mathrm{Rh}$ can be used and the results indicate its effectiveness and its performance is equal or superior than that verified for the universal chemical modifier [12].

ICP-OES offers the great advantage of multi-elemental detection, but does not present detection limits compatible with cadmium trace determinations. Finally, ICP-MS associates multi-elemental quantification and detection limits exceptionally reduced.

Related to sample composition, FAAS and ICP-OES exhibit tolerances higher than that presented by GFAAS and ICP-MS. Thus, some matrices as seawater with elevated saline contents can make the quantification of metallic ions difficult. In this specific case, atomisation is damaged in GFAAS while, in ICPMS, it is possible to observe salt deposition on the equipment interfaces [13].

To solve the small sensitivity of the FAAS and ICP-OES techniques and the concomitant effects observed in the GFAAS and 
Table 1

Cadmium preconcentration by electrochemical deposition

\begin{tabular}{llll}
\hline Matrix & $\begin{array}{l}\text { Preconcentration } \\
\text { factor }\end{array}$ & Technique & Reference \\
\hline Fresh waters & 26 & FAAS & {$[22]$} \\
Natural waters & 20 & FAAS & {$[23]$} \\
Groundwater and tap water & 60 & GFAAS & {$[24]$} \\
Seawater & 8 & GFAAS & {$[25]$} \\
Urine and river water & - & GFAAS & {$[26]$} \\
\hline
\end{tabular}

FAAS: flame atomic absorption spectrometry; GFAAS: graphite furnace atomic absorption spectrometry.

ICP-MS, numerous preconcentration and/or separation procedures are described in the literature [14].

In spite of the success attributed to direct determinations [15-21] by ICP-OES, preconcentration/separation procedures should be employed in order to eliminate concomitants able to provoke spectral interferences. For cadmium determination, some of its sensitive emission lines (214.38, 228.802 and $226.502 \mathrm{~nm}$ ) cannot be used in the presence of iron, aluminium and arsenic, respectively. For iron and aluminium, spectral interferences are especially dangerous because of their high concentrations in numerous samples as environmental and biological matrices. In this sense, cadmium determinations in the cited samples are affected by a considerable sensitivity decrease.

In order to complement the information set about cadmium preconcentration procedures coupled to atomic spectrometry techniques, this review considers publications related to solid-liquid and liquid-liquid extractions (LLE), electrochemical deposition, coprecipitation, as well as precipitation.

\section{Modalities of cadmium preconcentration procedures}

\subsection{Electrochemical deposition}

This modality utilises the electrolysis laws in which cationic species are deposited on the electrodes surface. When an electrolytic cell composed by three electrodes (reference, work and auxiliary) is used, it is possible to attained selective separation and preconcentration of cadmium. As example, Bulska et al. [22] achieved an enrichment factor of 26 for Cd(II) in fresh waters. This selective preconcentration was possible by operating the cell during $2 \mathrm{~min}$ in a system coupled to flame atomic absorption spectrometer. Abdullin et al. [23] also preconcentrated $\mathrm{Cd}(\mathrm{II})$ from natural waters and obtained an enrichment of 20 times by means of coupling a flame atomic absorption spectrometer to an electrolytic device. Table 1 contains others publications concerning with electrochemical preconcentration of cadmium. In spite of the desirable features of this modality, it also presents some drawbacks associated with laborious system operation and hydrogen generation in more negative potentials for acidic samples.

\subsection{Coprecipitation and precipitaton}

Precipitation comprises the generation of cadmium insoluble compounds from matrix samples. Generally, the procedures are carried out by adding to the samples reagents including $\mathrm{NaOH}$ and $\mathrm{NH}_{3}$ with a posterior acidic dissolution of the precipitate. On the other hand, coprecipitation is used when cadmium is presented at very low levels, thus not permitting that the solubility product constants be attained. In these cases, cadmium is retained on surface of precipitates as $\mathrm{Al}(\mathrm{OH})_{3}, \mathrm{Mg}(\mathrm{OH})_{2}$ and organic compounds [27]. Interesting publications related to cadmium enrichment by precipitation or coprecipitation are listed in the Table 2.

These preconcentration modalities can involve sample contamination, because chemicals are employed in large quantities when compared with the cadmium concentrations generally presented at $\mu \mathrm{g} \mathrm{L}^{-1}$ or $\mathrm{ng} \mathrm{L}^{-1}$ levels.

Knotted reactors (KR) are generally made from PTFE tubing, however other materials can are used for on-line precipitation or coprecipitation. They present internal diameter between 0.5 and $1.5 \mathrm{~mm}$ and are made from tubing by tying interlaced knots. The knotted reactors were used for first time as filterless collectors of organic precipitates in on-line coprecipitation-dissolution systems coupled to flame atomic absorption spectrometer [33]. During the investigation of the DDC complexes sorption on $\mathrm{C}_{18}$ microcolumns, a particular interaction of such complexes with hydrophobic tubing material was observed. The KR produced from PTFE tubes was able to retain metal complexes of DDC under appropriate experimental conditions and, since then, several works have been developed.

Two factors are responsible for retention of the complex molecules on the wall of the knotted reactors. Firstly, these molecular species are launched at inner wall of the KR's for action of the centrifugal force generated by secondary flows. The second reason is related to the nature of the material that form the KR and the nature of the complex [34]. The KR has been successfully adapted for flow injection in on-line pre-

Table 2

Cadmium preconcentration by coprecipitation or precipitation

\begin{tabular}{lllccc}
\hline Matrix & Modality & Coprecipitation or precipitation agents & Preconcentration factor & Technique & Reference \\
\hline Natural waters and soils & $\mathrm{CP}$ & DDTC-Cu(II) & 26 & FAAS & [28] \\
Molluscs & $\mathrm{P}$ & Iodine and quinine & 32 & FAAS \\
Dialysis concentrate & $\mathrm{CP}$ & DDTC-Co(II) & 75 & FAAS \\
Seawater & $\mathrm{CP}$ & DDTC-Co(II) & 225 & [30] & FAAS \\
Seawater & $\mathrm{CP}$ & $\mathrm{Mg}(\mathrm{OH})_{2}$ & $40-90$ & {$[30]$} & ICP-MS \\
Soils & $\mathrm{CP}$ & $\mathrm{BP}$ and DBQ & 400 & {$[31]$} & FAAS
\end{tabular}

CP: Coprecipitation; DDTC: diethyldithiocarbamate; P: precipitation; BP: Benzophenone; DBQ: 5,7-dibromoquinoline-8-ol; FAAS: flame atomic absorption spectrometry; ICP-MS: inductively coupled plasma mass spectrometry. 
Table 3

Cadmium preconcentration by using knotted reactor

\begin{tabular}{llll}
\hline Matrix & $\begin{array}{l}\text { Preconcentration } \\
\text { factor }\end{array}$ & Technique & Reference \\
\hline Rice and human hair & 66 & FAAS & {$[34]$} \\
Drinking water & 18 & FAAS & {$[36]$} \\
Water & 23 & FAAS & {$[37]$} \\
Honey & 40 & FAAS & {$[38]$} \\
Wine & 18 & ICP-OES & {$[39]$} \\
Rain and sea water & 33 & FAAS & {$[40]$} \\
Waters, soils, mussel & 65 & FAAS & {$[41]$} \\
$\quad$ and human hair & & & \\
Blood & 26 & GFAAS & {$[42]$} \\
Waters and soils & 26 & FAAS & {$[43]$} \\
Blood & 16 & GFAAS & {$[44]$} \\
Biological samples & 24 & FAAS & {$[45]$} \\
\hline
\end{tabular}

FAAS: flame atomic absorption spectrometry; GFAAS: graphite furnace atomic absorption spectrometry; ICP-OES: inductively coupled plasma optical emission spectrometry.

concentration with several spectrometric techniques for trace metals analysis [35]. Table 3 lists publications about the KR uses in on-line cadmium preconcentration from several types of samples.

\subsection{Liquid-liquid extraction}

LLE presents many applications related to determination of elements at extremely low concentrations in complex matrices such as environmental or biological samples. The LLE procedures are based on the relative solubility of the elements in two immiscible phases objecting both to improve the selectivity by separation of analyte and increase the sensitivity of the method. This target can be attained concentrating or isolating the analyte at the same phase where the analytical signal will be acquired [46].

To isolate the analyte by liquid-liquid extraction it is desired that the analyte to be quantitatively removed from aqueous matrix sample by adding immiscible solvents. On other hand, the interferent species must remain in the aqueous phase. The efficiency of this process depends on the affinity of analytes with the extracting solvent, ratio between the phases and number of extractions. In spite of its efficiency for removing interferents, LLE is expensive, slow and presents high consumption of toxic organic compounds [47], which can be harmful to the environment and the public health. Analytical procedures for cadmium separation and preconcentration by LLE and determination by spectrometric techniques are listed in Table 4.

\subsection{Cloud point extraction}

The separations and preconcentrations of metal ions, after the formation of sparingly water-soluble complex, based on cloud point extraction (CPE) have been largely employed in analytical chemistry. The cloud point procedure offers convenience and simplicity when compared with LLE modality, including higher extraction and preconcentration factors, lower cost and lower toxicity for the analyst and the environment. The procedure is based on the properties of non-ionic or amphoteric surfactants at levels upper to their critical micellar concentrations (CMC). Above CMC, a system composed by a unique phase is separated into two isotropic phases if some condition such as temperature or pressure is changed or if an appropriate substance is added to the solution [61]. Micelles formed from surfactant molecules act as organic solvents in liquid-liquid extraction and the analytes are partitioned between the micellar and aqueous phases [62]. In the micellar structure, there are numerous hydrophilic groupings responsible for a very efficient extraction of metallic species. For a more detailed discussion about CPE phenomenon, it is recommended to consult the literature [63].

As already commented, the addition of electrolytes can increase or decrease the surfactant cloud point, being these effects respectively known as "salting-in" and "salting-out". For micellar medium formed by pure non-ionic surfactants the cited phenomenon has a minor magnitude. Coelho and Arruda [64] investigate a cloud point separation induced by $\mathrm{NaCl}$ for extracting and pre-concentrating cadmium ions in physiological

Table 4

Cadmium preconcentration by conventional liquid-liquid extraction

\begin{tabular}{|c|c|c|c|c|c|}
\hline Matrix & Technique & Complexation agents & Solvent & Preconcentration factor & Reference \\
\hline Table salt & FAAS & Dithizone & Ethanol & 86 & {$[48]$} \\
\hline Natural water & FAAS & APDC & MIBK & 155 & [49] \\
\hline Estuarine water & GFAAS & $\mathrm{PDC} / \mathrm{DDC}$ & Chloroform & - & {$[50]$} \\
\hline Water & ST & PAN & Chloroform & - & [51] \\
\hline Water & FAAS & HPMSP/DDA & Toluene & - & [52] \\
\hline Water & GFAAS & PC-88A & Kerosene & 880 & {$[53]$} \\
\hline Biological materials & ICP-MS & $\mathrm{NaDDC}$ & Chloroform & - & [54] \\
\hline River water & FAAS & DDTC $^{\mathrm{j}}-\mathrm{MIBK}$ & - & - & {$[55]$} \\
\hline Natural water & FAAS & Dithizone & $\mathrm{HNO}_{3}$ & 331 & {$[56]$} \\
\hline Natural water & FAAS & Dithizone & Xylene & - & {$[57]$} \\
\hline Seawater & ICP-MS & DDC & - & - & {$[58]$} \\
\hline Water & FAAS & APDC & MIBK & - & [59] \\
\hline Phosphoric acid & FAAS & Kelex $100^{\circledR}$ & Kerosene & - & {$[60]$} \\
\hline
\end{tabular}

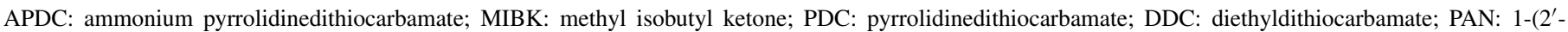

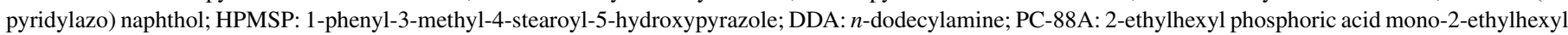

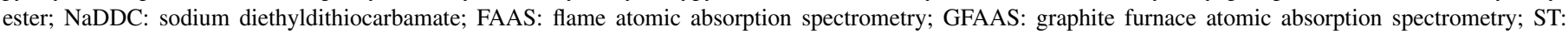
spectrophotometry; ICP-MS: inductively coupled plasma mass spectrometry. 
solution, mineral and lake waters and cigarette samples. A great advantage of this work comprises the low temperature $\left(25^{\circ} \mathrm{C}\right)$ required for forming the two phases. In this specific case, the cadmium was quantified by FAAS technique.

Table 5 lists recent works concerning with cadmium preconcentration by CPE and determination by atomic spectrometry techniques.

\subsection{Solid-liquid extraction}

This preconcentration category presents a remarkable set of desirable characteristics when applied for quantifying cadmium ions in samples such as waters, foods, pharmaceuticals, rocks, soils, sediments as well as plant and animal tissues. The main advantages conglomerate facility of system operation as well as expressive preconcentration factors.

Numerous sorbents are employed in cadmium preconcentration procedures based on solid-liquid extraction, including synthetic and natural materials. In addition, cadmium can also be preconcentrated in knotted reactors where the analyte is retained on the inner walls of small tubes.

\subsubsection{Use of synthetic sorbents}

Many materials, such as divinylbenzene polymers, zeolites, fullerenes and polyurethane foam are employed for preconcentration of cadmium ions. From these materials, chelating resins can be prepared by means of different procedures as discussed below. Chelating resins are especially interesting due to their higher selectivity when compared with single polymeric matrices.

Complexing reagents can be introduced into the sorbent by two different means: (1) the chemical bonding of these reagents on existing sorbents (functionalized sorbents); and (2) the physical binding of the chelating ligand on the sorbent by impregnating the solid matrix with a solution containing specific molecules (loaded sorbents) [72]. Physical binding is the most simple to be used in practice. However, chemical bonding allows elevated lifetime for column due to covalent bonds between the ligand and the support. This property avoids the possible flush of the ligand molecule from the column during sample percolation or elution steps. Several complexing reagents have been immobilized on a variety of solid matrices and successfully used for the preconcentration and determination of cadmium. The sorbents most largely associated with complexing substances to produce potential collectors of analytes are polystyrene-divinylbenzene [73], polyurethane foam [74], silica [75] and naphthalene [76]. Table 6 contains interesting works concerning with the cadmium preconcentration by using synthetic resins.

\subsubsection{Use of natural sorbents}

Madrid and Cámara [100] described the characteristics responsible for the metallic ions retention on microbial cells. This phenomenon is efficient because the cell membranes contain many chemical groups able to catch ions [101]. In general, this same structural feature is also valid for a great variety of different natural substrates, including bark/tannin-rich materials, lignin, chitin/chitosan, dead biomass, seaweed/algae/alginate, xanthate, zeolite, clay, fly ash, humified materials, bone gelatin beads, leaf mould, moss, iron-oxide-coated sand, modified wool and cotton [102]. Further, extensive surface area and porosity attribute to natural sorbents excellent properties for retaining cations or anions. However, natural materials present poor selectivity due to the predominance of electrostatic forces among sites (placed on their surfaces) and analytes. In this sense, unspecific retentions are observed. This limitation does not comprise a serious problem for wastewater treatment, where retentiveness of diverse pollutants is desired and it is necessary only to increase sorbent masses when saturations are attained. In this way, the literature [102] deals with the use of natural substrates for treating effluents produced by industries and laboratories.

One another hand, preconcentration demands high selectivity for attaining desirable analytical performance. As already commented, natural materials are unspecific because of their electrostatic interactions with cationic species. In addition, these sorbents present low uniformity composition and, obviously, this aspect can damage the precision and accuracy of the results. Pereira and Arruda [14] reported a great number of procedures devoted to metal preconcentration (including cadmium) based on solid-liquid extractions. As expected, the majority of the cited works employed synthetic sorbents, such as amberlites, activated carbon, $\mathrm{C}_{18}$, fullerenes, polyurethane foam and PTFE, while microbial biomass comprised the main category of natural preconcentrators. In spite of the greater tendency in use synthetic sorbents, there are some interesting applications of natural preconcentrators as described in Table 7 .

Table 5

Cadmium preconcentration by cloud point extraction

\begin{tabular}{|c|c|c|c|c|}
\hline Matrix & Complexing/surfactant & Preconcentration factor & Technique & Reference \\
\hline Physiological solution, mineral and lake waters and tobacco & DDTP/Triton X-114 & - & FAAS & [64] \\
\hline Waters & DDTP/Triton X-114 & 29 & ICP-MS & [65] \\
\hline Seawater & PAN & 120 & FAAS & {$[66]$} \\
\hline Biological materials & DDTP/Triton X-114 & 129 & GFAAS & [67] \\
\hline Waters & TAN/Triton X-114 & 58 & FAAS & {$[68]$} \\
\hline Human hair & DDTP/Triton X-114 & 22 & FAAS & [69] \\
\hline Waste and waters & Dithizone/Triton X-114 & 52 & FAAS & {$[70]$} \\
\hline Seawater & DDTC/Triton X-114 & 52 & GFAAS & [71] \\
\hline
\end{tabular}

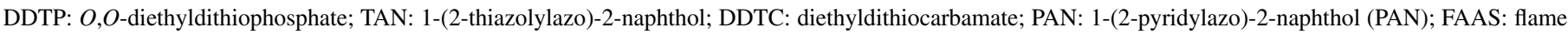
atomic absorption spectrometry; ICP-MS: inductively coupled plasma mass spectrometry; GFAAS: graphite furnace atomic absorption spectrometry. 
Table 6

Cadmium preconcentration by solid-liquid extraction (synthetic sorbents)

\begin{tabular}{|c|c|c|c|c|c|}
\hline Matrix & Sorbent & Chelating material & Technique & $\begin{array}{l}\text { Preconcentration } \\
\text { factor }\end{array}$ & Reference \\
\hline Biological reference materials & Amberlite XAD-2 & TAM & FAAS & 108 & [72] \\
\hline Water & Amberlite XAD-2 & AT & FAAS & 28 & [73] \\
\hline $\begin{array}{l}\text { Black tea, spinach leaves, natural and } \\
\text { tap water }\end{array}$ & PUF & Me-BTANC & FAAS & 37 & [74] \\
\hline Water & Silica gel 60 & Aspergillus niger (Fungi) & FAAS & - & [75] \\
\hline $\begin{array}{l}\text { Standard alloy, various biological } \\
\text { and environmental samples }\end{array}$ & NAP & TAN-TPB & DPP & - & [76] \\
\hline $\begin{array}{l}\text { Water, soil, and roadside dust } \\
\text { samples }\end{array}$ & Amberlyst 36 & - & FAAS & 200 & {$[77]$} \\
\hline Fresh water & Amberlite & TAM & FAAS & 548 & [78] \\
\hline Biological reference materials & PUF & BTAC & FAAS & 41 & [79] \\
\hline Water & Zeolite A4 & - & GFAAS & - & [80] \\
\hline Milk products & Chelite P & AMPA & FAAS & 20.5 & [81] \\
\hline $\begin{array}{l}\text { Stream sediment, sewage sludge and } \\
\text { sea water }\end{array}$ & Chelex 100 & - & FAAS & - & [82] \\
\hline Water and salts & Chromosorb-106 & PAN & FAAS & - & {$[83]$} \\
\hline Water & Silica gel & Thioacetamide & FAAS & 200 & [84] \\
\hline $\begin{array}{l}\text { Environmental and biological } \\
\text { samples }\end{array}$ & Silica gel & Thiol & FAAS & 56 & [85] \\
\hline Biological samples & Amberlite XAD-4 & DDTP & FAAS & - & [86] \\
\hline Water & Dowex 1-X10 & Dithizone & FAAS & - & [87] \\
\hline- & PUF & DDTC & FAAS & - & [88] \\
\hline- & QAE-Sephadex & TATS & GFAAS & 200 & [89] \\
\hline- & Chromosorb-107 & APDC & GFAAS & - & [90] \\
\hline Tea & Cyanex 923 & - & HG-AFS & 200 & [91] \\
\hline Certified river sediment & Imprinted resin (poly-Cd(II)-DAAB-VP & - & FAAS & - & [92] \\
\hline Biological samples & Amberlite XAD-2 & $\mathrm{CA}$ & FAAS & 21 & [93] \\
\hline Soils & NAP & Xanthate and PN & FAAS & 200 & [94] \\
\hline Wine & $\mathrm{C}-18$ bonded silica gel & ADDP & FAAS & 11 & [95] \\
\hline Water & Amberlite XAD-16 & PAN & FAAS & 200 & [96] \\
\hline Water & Silica gel & DHAQ & FAAS & - & [97] \\
\hline Saline matrices & NAP & Dithizone & ICP-OES & - & [98] \\
\hline Alloys and waters & $\mathrm{AC}$ & Zn-PDTC & FAAS & _- & [99] \\
\hline
\end{tabular}

TAM: 2-(2-thiazolylazo)-5-dimethylaminophenol; AT: 2-aminothiophenol; PUF: polyurethane foam; Me-BTANC: 2-(6-methyl-2-benzothiazolylazo) chromotropic acid; NAP: microcrystalline naphthalene; TAN: 1-(2-thiazolylazo)-2-naphthol; TPB: tetraphenylborate; BTAC: 2-(2'-benzothiazolylazo)-p-cresol; AMPA: aminomethylphosphoric acid; PAN: 1-(2-pyridylazo) 2-naphthol; DDTP: $O, O$-diethyldithiophosphate; DDTC: diethyldithiocarbamate; TATS: thiacalix[4]arenetetrasulfonate; APDC: ammonium pyrrolidinedithiocarbamate; CA: chromotropic acid; DAAB: diazoaminobenzene; VP: 4-vinylpyridine; PN: 1, 10phenanthroline; ADDP: ammonium diethyldithiophosphate; DHAQ: 1,8-dihydroxyanthraquinone; AC: activated carbon; Zn-PDTC: zinc-piperazinedithiocarbamate; FAAS: flame atomic absorption spectrometry; GFAAS: graphite furnace atomic absorption spectrometry; DPP: differential pulse polarography; HG-AFS: hydride generation atomic fluorescence spectrometry; ICP-OES: inductively coupled plasma optical emission spectrometry.

Pereira and Arruda [103] developed methodologies for determining $\mathrm{Cd}(\mathrm{II})$ in water and biological samples. In this case, humic substances (vermicompost and purified humic acid), were packed in small columns coupled to a flame atomic absorption spectrometer. The authors obtained good stability of the column (for 100 successive analyse cycles, for both sorbents), but poor selectivity was observed when cadmium was preconcentrated concomitantly with others metallic cations, such as calcium, magnesium, chromium, copper, nickel and zinc. Minamisawa et al. [80] showed that it is possible to enrich $\mathrm{Cd}(\mathrm{II})$ on rice husks also by employing on-line systems coupled to a flame atomic absorption spectrometer. In this case, a theoretical pre-

Table 7

Cadmium preconcentration by liquid-solid extraction (natural sorbents)

\begin{tabular}{|c|c|c|c|c|}
\hline Matrix & Natural sorbent & $\begin{array}{l}\text { Preconcentration } \\
\text { factor }\end{array}$ & Technique & Reference \\
\hline Mineral and tap waters, pharmaceuticals, fruit juice, pig kidney and beech leaves & Purified humic acid & 83 & FAAS & [103] \\
\hline Mineral and tap waters, pharmaceuticals, fruit juice, pig kidney and beech leaves & Vermicompost & 62 & FAAS & [103] \\
\hline- & Rice husks & 72 & FAAS & [104] \\
\hline Waters & Yeast $($ S. cerevisiae $)$ & 10 & FAAS & {$[105]$} \\
\hline Alloys & Bacterium (E. coli) & 10 & FAAS & [106] \\
\hline Domestic sewage loam & Yeast $(S$. cerevisiae $)$ & 250 & FAAS & [107] \\
\hline
\end{tabular}

FAAS: flame atomic absorption spectrometry. 
concetration factor of 72 was calculated. Nevertheless, foreign ions presented strong competition with $\mathrm{Cd}(\mathrm{II})$ when real samples were analysed. Again, this limitation reduced the sensibility.

In the both works above commented, calibration procedures based on the aqueous standard solutions were not possible. It was necessary to adopt the standard addition procedure in order to solve the serious effects presented by the matrices.

\section{Conclusions}

It was possible to identify different possibilities for preconcentrating cadmium ions from numerous matrices. Correct choices can be obtained by means of rigorous analyses associated with sample throughput and disponibility, cadmium concentration, desired preconcentration factors, among others. In this context, solid-liquid extractions (by using synthetic or natural sorbents) comprise a good alternative for cadmium determination in samples such as natural waters, foods and beverages. One another hand, this modality is not recommended for small quantities of samples as biological fluids. In these specific cases, cloud point extractions can be successfully employed due to their reduced requirements of sample volume. Conventional liquid-liquid extractions present limitations with the use of extensive toxic solvents and, for this reason, they tend to be avoided.

Coprecipitation and precipitation procedures offer attractive characteristics related to preconcentration capacity. Nevertheless, special cautions should be considered in order to avoid contaminations derived from the great excess of added substances in the reaction medium. Electrochemical devices, when adopted in cadmium preconcentration, are able to associate sensibility and selectivity. In this way, matrices containing many potential interferents (seawater, for example) can be satisfactorily analysed by choosing the best electrodepositing potential.

On-line systems are preferred due to the automatisation facility. In addition, the lower sample and reagent consumptions are compatible with the green chemistry principles. Flame atomic absorption and inductively coupled plasma optical emission spectrometers exhibits a greater number of applications with on-line preconcentration systems, because of their continuous operation mode. In contrast, the equipments employed in GFAAS require discontinuous heating programmes, thus carrying out more sophisticated preconcentrations systems.

Finally, preconcentration procedures for cadmium comprise an important tool for developing sensible methodologies with economic viability.

\section{Acknowledgements}

The authors are grateful to the CNPq (Conselho Nacional de Desenvolvimento Tecnológico, Brasília, Brazil) and FAPESB (Fundação de Amparo a Pesquisa do Estado da Bahia, Salvador, Brazil) for fellowships and financial supports.

\section{References}

[1] N.N. Greenwood, A. Earnshaw, Chemistry of the Elements, Pergamon Press, Oxford, 1989.

[2] F.A. Cotton, G. Wilkinson, C.A. Murillo, M. Bochmann, Advanced Inorganic Chemistry, sixth ed., John Wiley \& Sons INC, New York, 1999.

[3] http://www.theodoregray.com accessed in April 10, 2006.

[4] http://www.webelements.com accessed in April 10, 2006.

[5] http://www.cadmium.org accessed in April 10, 2006.

[6] http://www.atsdr.cdc.gov accessed in April 10, 2006.

[7] A.C. Davis, P. Wu, X. Zhang, X. Hou, B.T. Jones, Determination of cadmium in biological samples, Appl. Spectrosc. Rev. 41 (2006) 35-75.

[8] J.H. Mennear, Cadmium Toxicity, Dekker, New York, 1979.

[9] B. Welz, M. Sperling, Atomic Absorption Spectrometry, third ed., WileyVCH, Weinheim, New York, 1999.

[10] M.L. Garrido, R. Munõz-Olivas, C. Cámara, Interference removal for cadmium determination in waste water and sewage sludge by flow injection cold vapor generation atomic absorption spectrometry, J. Anal. At. Spectrom. 13 (1998) 1145-1149.

[11] D.J. Butcher, Advances in Electrothermal Atomization Atomic Absorption Spectrometry: Instrumentation, Methods, and Applications, Appl. Spectrosc. Rev. 41 (2006) 15-34.

[12] C.S. Nomura, P.R.M. Correia, P.V. Oliveira, E. Oliveira, W + Rh as permanent chemical modifier in simultaneous atomic absorption spectrometry: interference studies on $\mathrm{As}, \mathrm{Cd}, \mathrm{Pb}$ and $\mathrm{Se}$ determination, J Braz. Chem. Soc. 15 (2004) 75-82.

[13] J.W. Robinson, Atomic Spectroscopy, Marcel Dekker, Inc, New York, 1996.

[14] M.G. Pereira, M.A.Z. Arruda, Trends in preconcentration procedures for metal determination using atomic spectrometry techniques, Microchim. Acta 141 (2003) 115-131.

[15] A.E. Pillay, J.R. Williams, M.O. El Mardi, S.M. Hassan, A. Al-Hamdi, Monitoring of cadmium in "on" and "off" date palms, Environ. Int. 28A (2002) 273-276.

[16] A. Ikem, A. Nwankwoala, S. Odueyungbo, K. Nyavor, N. Egiebor, Levels of 26 elements in infant formula from USA, UK, and Nigeria by microwave digestion and ICP-OES, Food Chem. 77 (2002) 439447.

[17] A. Angioni, M. Cabitza, M.T. Russo, P. Caboni, Influence of olive cultivars and period of harvest on the contents of $\mathrm{Cu}, \mathrm{Cd}, \mathrm{Pb}$, and $\mathrm{Zn}$ in virgin olive oils, Food Chem. 99 (2006) 525-529.

[18] A. Matsumoto, T. Kobata, T. Nakahara, Determination of cadmium in polyethylene by analytical atomic spectrometry with gas-phase sample introduction technique, Microchem. J. 76 (2004) 43-51.

[19] K. Sreenivasa Rao, T. Balaji, T. Prasada Rao, Y. Babu, G.R.K. Naidu, Determination of iron, cobalt, nickel, manganese, zinc, copper, cadmium and lead in human hair by inductively coupled plasma atomic emission spectrometry, Spectrochim. Acta B 57 (2002) 1333-1338.

[20] P. Smichowski, J. Marrero, D. Gomez, Inductively coupled plasma optical emission spectrometric determination of trace element in PM10 airborne particulate matter collected in an industrial area of Argentina, Microchem. J. 80 (2005) 9-17.

[21] D.C. Lambkin, B.J. Alloway, The problem of arsenic interference in the analysis of soils for cadmium by inductively coupled plasma optical emission spectrometry, Sci.Total Environ. 256 (2000) 77-81.

[22] E. Bulska, M. Walcerz, W. Jedral, A. Hulanicki, On-line preconcentration of lead and cadmium for flame atomic absorption spectrometry using a flow-through electrochemical microcell, Anal. Chim. Acta 357 (1997) 133-140.

[23] I.F. Abdullin, E.N. Turova, G.K. Budnikov, Determination of copper and cadmium by atomic absorption spectrometry with electrochemical and sorption preconcentration, J. Anal. Chem. 55 (2000) 567-569.

[24] J. Komárek, J. Holý, Determination of heavy metals by electrothermal atomic absorption spectrometry after electrodeposition on a graphite probe, Spectrochim. Acta B 54 (1999) 733-738.

[25] J. Knápek, J. Komarék, P. Krásenský, Determination of cadmium by electrothermal atomic absorption spectrometry by using electrochemical separation in a microcell, Spectrochim. Acta B 60 (2005) 393-398. 
[26] G. Zhang, J. Li, D. Fu, D. Hao, P. Xiang, Atomic absorption determination of traces of cadmium in urine after electrodeposition onto a tungsten wire, Talanta 40 (1993) 409-413.

[27] H.A. Mackenzie, L.E. Smythe, Quantitative Trace Analysis of Biological Materials, Elsevier, New York, 1988.

[28] H. Chen, J. Jin, Y. Wang, Flow injection on-line coprecipitationpreconcentration system using copper(II) diethyldithiocarbamate as carrier for flame atomic absorption spectrometric determination of cadmium, lead and nickel in environmental samples, Anal. Chim. Acta 353 (1997) 181-188.

[29] M.C. Yebra, M.F. Enríquez, R.M. Cespón, Preconcentration flame atomic absorption spectrometry determination of cadmium in mussels by an online precipitation dissolution flow system, Talanta 52 (2000) 631-636.

[30] L. Elçi, U. Sahin, S. Oztas, Determination of trace amounts of same metals in samples with high salt content by atomic absorption spectrometry after cobalt-diethyldithiocarbamate coprecipitation, Talanta 44 (1997) 1017-1023.

[31] J. Wu, E.A. Boyle, Low blank preconcentration technique for the determination of lead, copper and cadmium in small-volume seawater samples by isotope dilution ICP-MS, Anal. Chem. 69 (1997) 2464-2470.

[32] K. Prasad, P. Gopikrishna, R. Kala, T.P. Rao, G.R.K. Naidu, Solid phase extraction vis-à-vis coprecipitation preconcentration of cadmium and lead from soils onto 5,7-dibromoquinoline-8-ol embedded benzophenone and determination by FAAS, Talanta 69 (2006) 938-945.

[33] Z.L. Fang, M. Sperling, B. Welz, Flame atomic-absorption spectrometric determination of lead in biological samples using a flow-injection system with online preconcentration by coprecipitation without filtration, J. Anal. At. Spectrom. 6 (1991) 301-306.

[34] Z.L. Fang, S.K. Xu, L.P. Dong, W.Q. Li, Determination of cadmium in biological-materials by flame atomic absorption spectrometry with flow injection on-line sorption preconcentration, Talanta 41 (1994) 2165-2172.

[35] S. Cerutti, R.G. Wuilloud, L.D. Martinez, Knotted reactors and their role in flow injection on-line preconcentration systems coupled to atomic spectrometry-based detectors, Appl. Spectrosc. Rev. 40 (2005) 71-101.

[36] A.S. Souza, W.N.L. dos Santos, S.L.C. Ferreira, Application of BoxBehnken design in the optimisation of an on-line preconcentration system using knotted reactor for cadmium determination by flame atomic absorption spectrometry, Spectrochim. Acta B 60 (2005) 737-742.

[37] S. Cerutti, S.LC. Ferreira, J.A. Gasquez, R.A. Olsina, L.D. Martinez, Optimization of the preconcentration system of cadmium with 1(2thiazolylazo)- $p$-cresol using a knotted reactor and flame atomic absorption spectrometric detection, J. Hazard. Mater. 112 (2004) 279-283.

[38] R.F. Orsi, R.G. Wuilloud, J.C.A. de Wuilloud, R.A. Olsina, L.D. Martinez, On-line preconcentration and determination of cadmium in honey using knotted reactor coupled to flow injection-flame atomic absorption spectrometry, J. AOAC Int. 85 (2002) 1410-1414.

[39] R.F. Lara, R.G. Wuilloud, J.A. Salonia, R.A. Olsina, L.D. Martinez, Determination of low cadmium concentrations in wine by on-line preconcentration in a knotted reactor coupled to an inductively coupled plasma optical emission spectrometer with ultrasonic nebulization, Fresenius J. Anal. Chem. 371 (2001) 989-993.

[40] I. Garrido, R.M. Soto, A. Carlosena, Flame atomic absorption spectrometry with flow injection on-line adsorption preconcentration using a knotted reactor for cadmium determination in aqueous samples, Anal. Lett. 34 (2001) 1763-1779.

[41] J.S. Liu, H.W. Chen, X.Q. Mao, Determination of trace copper, lead, cadmium, and iron in environmental and biological samples by flame atomic absorption spectrometry coupled to flow injection on-line coprecipitation preconcentration using DDTC-nickel as coprecipitate carrier, Int. J. Environ. Anal. Chem. 76 (2000) 267-282.

[42] E. Ivanova, W. Van Mol, F. Adams, Electrothermal atomic absorption spectrometric determination of cadmium and lead in blood using flow injection on-line sorption preconcentration in a knotted reactor, Spectrochim. Acta B 53 (1998) 1041-1048.

[43] H.W. Chen, J.C. Jin, Y.F. Wang, Flow injection on-line coprecipitationpreconcentration system using copper (II) diethyldithiocarbamate as carrier for flame atomic absorption spectrometric determination of cadmium, lead and nickel in environmental samples, Anal. Chim. Acta 353 (1997) 181-188.

[44] Z.L. Fang, L.P. Dong, Flow injection on-line coprecipitation preconcentration for electrothermal atomic absorption spectrometry, J. Anal. At. Spectrom. 7 (1992) 439-445.

[45] B. Welz, S.K. Xu, M. Sperling, Flame atomic absorption spectrometric determination of cadmium, cobalt, and nickel in biological samples using a flow injection system with online preconcentration by coprecipitation without filtration, Appl. Spectrosc. 45 (1991) 1433-1443.

[46] I. Facchin, C. Pasquini, Liquid-liquid extraction in flow systems, Quim. Nova 21 (1998) 60-68.

[47] F.E. Ahmed, Analysis of pesticides and their metabolites in foods and drinks, Trends Anal. Chem. 20 (2001) 649-661.

[48] F.A.C. Amorim, S.L.C. Ferreira, Determination of cadmium and lead in table salt by sequential multi-element flame atomic absorption spectrometry, Talanta 65 (2005) 960-964.

[49] A.N. Anthemidis, G.A. Zachariadis, C.G. Farastelis, J.A. Stratis, On-line liquid-liquid extraction system using a new phase separator for flame atomic absorption spectrometric determination of ultra-trace cadmium in natural waters, Talanta 62 (2004) 437-443.

[50] K. Ndung'u, R.P. Franks, K.W. Bruland, A.R. Flegal, Organic complexation and total dissolved metal trace metal analysis in estuarine waters: comparison of solvent-extraction graphite furnace atomic absorption spectrometric with chelating resin flow injection inductively coupled plasma-mass spectrometric analysis, Anal. Chim. Acta 481 (2003) 127-138.

[51] I. Facchin, C. Pasquini, Two-phase liquid-liquid extraction in monosegmented flow analysis. Determination of cadmium with 1-(2'-pyridylazo) naphtol, Anal. Chim. Acta 308 (1995) 231-237.

[52] G.J.G.G. Sigit, J.P. Brunette, Liquid-liquid extraction of cadmium and cobalt with mixtures of 1-phenyl-3-methyl-4-stearoyl-5-hydroxypyrazole (HPMSP) and $n$-dodecylamine (DDA) in toluene, Monatsh. Chem. 129 (1998) 787-797.

[53] Y. Okamoto, Y. Nomura, H. Nakamura, K. Iwamaru, T. Fujiwara, T. Kumamaru, High preconcentration of ultra-trace metal ions by liquid-liquid extraction using water/oil/water emulsions as liquid surfactant membranes, Microchem. J. 65 (2000) 341-346.

[54] R.A. Vandepool, W.T. Buckley, Liquid-liquid extraction of cadmium by sodium diethyldithiocarbamate from biological matrixes for isotope dilution inductively coupled mass spectrometry, Anal. Chem. 71 (1999) $652-659$.

[55] W.T. Jung, S.K. Kim, K.J. Lee, D.H. Sohn, Multi-element determination of heavy metals in the Han River of Korea using liquid-liquid extraction flame atomic absorption spectrometry, Jpn. J. Toxicol. Environ. Health 43 (1997) 243-250.

[56] E. Carasek, J.W. Tonjes, M. Scharf, A new method of microvolume backextraction procedure for enrichment of $\mathrm{Pb}$ and $\mathrm{Cd}$ and determination by flame atomic absorption spectrometry, Talanta 56 (2002) 185-191.

[57] E. Carasek, J.W. Tonjes, M. Scharf, A liquid-liquid microextraction system for $\mathrm{Pb}$ and $\mathrm{Cd}$ enrichment and determination by flame atomic absorption spectrometry, Quim. Nova 25 (2002) 748-752.

[58] G.J. Batterham, N.C. Munksgaard, D.L. Parry, Determination of trace metals in seawater by inductively coupled plasma mass spectrometry after off-line dithiocarbamate solvent extraction, J. Anal. At. Spectrom. 12 (1997) 1277-1280

[59] I.A. Ansari, V.K. Dewani, M.Y. Khuhawar, Evaluation of metal contents in Phulleli canal and Hyderabad city sewage by flame atomic absorption spectrometer, J. Chem. Soc. (Pakistan) 21 (1999) 359-368.

[60] A. Mellah, D. Benachour, Solvent extraction of heavy metals contained in phosphoric acid solutions by 7-(4-ethyl-1-methyloctyl)8-hydroxyquinoline in kerosene diluent, Hydrometallurgy 81 (2006) $100-103$.

[61] M. de, A. Bezerra, M.A.Z. Arruda, S.L.C. Ferreira, Cloud point extraction as a procedure of separation and preconcentration for metal determination using spectroanalytical techniques: a review, Appl. Spectrosc. Rev. 40 (2005) 269-299.

[62] D. Attwood, A.T. Florence, Surfactants Systems-Their Chemistry Pharmacy and Biology, Chapman and Hall, London, 1985. 
[63] A. Sanz-Mendel, M.R.F. de la Campa, E.B. Gonzalez, Fernández-Sanches F.M.L., Organised surfactant assemblies in analytical atomic spectrometry, Spectrochim. Acta B 54 (1999) 251-287.

[64] L.M. Coelho, M.A.Z. Arruda, Preconcentration procedure using cloud point extraction in the presence of electrolyte for cadmium determination by flame atomic absorption spectrometry, Spetrochim. Acta B 60 (2005) 743-748.

[65] M.A.M. da Silva, V.L.A. Frescura, A.J. Curtius, Determination of trace elements in water samples by ultrasonic nebulization inductively coupled plasma mass spectrometry after cloud point extraction, Spectrochim. Acta B 55 (2000) 803-813.

[66] C.G. Pinto, J.L.P. Pavón, B.M. Cordero, E.R. Beato, Cloud point preconcentration and flame atomic absorption spectrometry: application to the determination of cadmium, J. Anal. At. Spectrom. 11 (1996) 37-42.

[67] T.A. Maranhão, D.L.G. Borges, M.A.S. da Veiga, A.J. Curtius, Cloud point extraction for the determination of cadmium and lead in biological samples by graphite furnace atomic absorption spectrometry, Spectrochim. Acta B 60 (2005) 667-672.

[68] J. Chen, K.C. Teo, Determination of cadmium, copper, lead and zinc in water samples by flame atomic absorption spectrometry after cloud point extraction, Anal. Chim. Acta 450 (2001) 215-222.

[69] J.L. Manzoori, A. Bavili-Tabrizi, Cloud point preconcentration and flame atomic absorption spectrometric determination of $\mathrm{Cd}$ and $\mathrm{Pb}$ in human hair, Anal. Chim. Acta 470 (2002) 215-221.

[70] J.L. Manzoori, G. Karim-Nezhad, Development of a cloud point extraction and preconcentration method for $\mathrm{Cd}$ and $\mathrm{Ni}$ prior to flame atomic absorption spectrometric determination, Anal. Chim. Acta 521 (2004) 173-177.

[71] C.G. Yuan, G.B. Jiang, Y.Q. Cai, B. He, J.F. Liu, Determination of cadmium at the nanogram per liter level in seawater by graphite furnace AAS using cloud point extraction, Atom. Spectrom. 25 (2004) 170-176.

[72] M.H.A. Melo, S.L.C. Ferreira, R.E. Santelli, Determination of cadmium by FAAS after on-line enrichment using a mini column packed with Amberlite XAD-2 loaded with TAM, Microchem. J. 65 (2000) 59-65.

[73] V.A. Lemos, P.X. Baliza, Amberlite XAD-2 functionalized with 2aminothiophenol as a new sorbent for on-line preconcentration of cadmium and copper, Talanta 67 (2005) 564-570.

[74] E.M. Gama, A.S. Lima, V.A. Lemos, Preconcentration system for cadmium and lead determination in environmental samples using polyurethane foam/Me-BTANC, J. Hazard. Mater. 136 (2006) $757-$ 762.

[75] S. Baytak, A.R. Turker, B.S. Cevrimli, Application of silica gel 60 loaded with Aspergillus niger as a solid phase extractor for the separation/preconcentration of chromium(III), copper(II), zinc(II), and cadmium(II), J. Sep. Sci. 28 (2005) 2482-2488.

[76] A. Bhalotra, Atamiyot, B.K. Puri, Simultaneous determination of cadmium and lead in a standard alloy, various biological and environmental samples by differential pulse polarography after preconcentration by solid phase extraction of their 1-(2-thiazolylazo)-2-naphthol-tetraphenylborate complexes on microcrystalline naphthalene, Quim. Anal. 20 (2002) 229-236.

[77] E. Kenduzler, Determination of cadmium(II) in water and soil samples after preconcentration with a new solid phase extractor, Sep. Sci. Technol. 41 (2006) 1645-1659.

[78] W.N.L. dos Santos, C.M. dos Santos, S.L.C. Ferreira, Field sampling system for determination of cadmium and nickel in fresh water by flame atomic absorption spectrometry, J. Brazil. Chem. Soc. 16 (2005) 727-732.

[79] V.A. Lemos, R.E. Santelli, M.S. de Carvalho, S.L.C. Ferreira, Application of polyurethane foam loaded with BTAC in an on-line preconcentration system: cadmium determination by FAAS, Spectrochim. Acta B 55 (2000) $1497-1502$.

[80] H. Minamisawa, R. Okunugi, M. Minamisawa, S. Tanaka, K. Saitoh, N. Arai, M. Shibukawa, Preconcentration and determination of cadmium by GFAAS after solid phase extraction with synthetic zeolite, Anal. Sci. 22 (2006) 709-713.

[81] S. Cancela, M.C. Yebra, Flow injection flame atomic absorption spectrometric determination of trace amounts of cadmium in solid and semisolid milk products coupling a continuous ultrasound-assisted extraction system with the online preconcentration on a chelating aminomethylphosphoric acid resin, J. AOAC Int. 89 (2006) 185-191.

[82] M. Soylak, I. Narin, On-line preconcentration system for cadmium determination in environmental samples by flame atomic absorption spectrometry, Chem. Anal. (Warsaw) 50 (2005) 705-715.

[83] M. Tuzen, K. Parlar, M. Soylak, Enrichment/separation of cadmium(II) and lead(II) in environmental samples by solid phase extraction, J. Hazard. Mater. 121 (2005) 79-87.

[84] Z.H. Xie, F.Z. Xie, L.Q. Guo, X.C. Lin, G.N. Chen, Thioacetamide chemically immobilized on silica gel as a solid phase extractant for the extraction and preconcentration of copper(II), lead(II), and cadmium(II), J. Sep. Sci. 28 (2005) 462-470.

[85] G.Z. Fang, J. Tan, X.P. Yan, An ion-imprinted functionalized silica gel sorbent prepared by a surface imprinting technique combined with a solgel process for selective solid-phase extraction of cadmium(II), Anal. Chem. 77 (2005) 1734-1739.

[86] E.H. dos Santos, A.B. Herrmann, A.S. Ribeiro, A.J. Curtius, Determination of $\mathrm{Cd}$ in biological samples by flame AAS following on-line preconcentration by complexation with $O, O$-diethyldithiophosphate and solid phase extraction with amberlite XAD-4, Talanta 65 (2005) 593-597.

[87] M.S. Di Nezio, M.E. Palomeque, B.S.F. Band, Automated flow injection method for cadmium determination with preconcentration and on-line reagent preparation, Quim. Nova 28 (2005) 145-148.

[88] O.D. Sant'Ana, L.S. Jesuino, R.J. Cassella, M.S. Carvalho, R.E. Santelli, Solid-phase extraction of Cd(II) as diethyldithiocarbamate complex by polyurethane foam: Kinetic and thermodynamic characterization, Sep. Sci. Technol. 39 (2004) 2695-2709.

[89] H. Matsumiya, N. Iki, S. Miyano, M. Hiraide, Preconcentration of copper, cadmium, and lead with a loaded Sephadex A-25 anion-exchanger for graphite furnace atomic absorption spectrometry, Anal. Bioanal. Chem. 379 (2004) 867-871.

[90] N. Tokman, S. Akman, Determination of bismuth and cadmium after solid-phase extraction with chromosorb-107 in a syringe, Anal. Chim. Acta 519 (2004) 87-91.

[91] T.C. Duan, X.J. Song, D. Jin, H.F. Li, J.W. Wu, H.T. Chen, Preliminary results on the determination of ultratrace amounts of cadmium in tea samples using a flow injection on-line solid phase extraction separation and preconcentration technique to couple with a sequential injection hydride generation atomic fluorescence spectrometry, Talanta 67 (2005) 968974.

[92] Y.W. Liu, X.J. Chang, S. Wang, Y. Guo, B.J. Din, S.M. Meng, Solid phase extraction and preconcentration of cadmium $(\mathrm{H})$ in aqueous solution with $\mathrm{Cd}(\mathrm{II})$-imprinted resin (poly-Cd(II)-DAAB-VP) packed columns, Anal. Chim. Acta 519 (2004) 173-179.

[93] V.A. Lemos, L.S. Nunes, P.X. Baliza, J.S. Santos, R.T. Yamaki, A.A. de Jesus, On-line solid phase extraction system for cadmium preconcentration and determination by flame atomic absorption spectroscopy, Can. J. Anal. Sci. Spectrosc. 49 (2004) 24-30.

[94] P.G. Krishna, K.S. Rao, V.M. Biju, T.P. Rao, G.R.K. Naidu, Simultaneous preconcentration of $\mathrm{Cu}, \mathrm{Cd}$ and $\mathrm{Pb}$ from soil samples by solid phase extraction and their determination by flame AAS, Chem. Anal. (Warsaw) 49 (2004) 383-393.

[95] A.P. Fernandes, M. de Moraes, J.A.G. Neto, Flow injection AAS determination of $\mathrm{Cd}, \mathrm{Cu}$, and $\mathrm{Pb}$ at trace levels in wine using solid phase extraction, Atom. Spectrosc. 24 (2003) 179-184.

[96] I. Narin, M. Soylak, K. Kayakirilmaz, L. Elçi, M. Dogan, Preparation of a chelating resin by immobilizing 1-(2-pyridylazo) 2-naphtol on amberlite XAD-16 and its application' of solid phase extraction of $\mathrm{Ni}(\mathrm{II}), \mathrm{Cd}(\mathrm{II})$, $\mathrm{Co}(\mathrm{II}), \mathrm{Cu}(\mathrm{II}), \mathrm{Pb}(\mathrm{II})$, and $\mathrm{Cr}(\mathrm{III})$ in natural water samples, Anal. Lett. 36 (2003) 641-658.

[97] A. Goswami, A.K. Singh, 1,8-dihydroxyanthraquinone anchored on silica gel: synthesis and application as solid phase extractant for lead(II), zinc(II) and cadmium(II) prior to their determination by flame atomic absorption spectrometry, Talanta 58 (2002) 669-678.

[98] A.C.S. Costa, L. Lopes, M.D.A. Korn, J.G. Portela, Separation and preconcentration of cadmium, copper, lead, nickel and zinc by solid-liquid extraction of their cocrystallized naphthalene dithizone chelate in saline matrices, J. Brazil. Chem. Soc. 13 (2002) 674-678. 
[99] H. Cesur, M. Macit, B. Bati, Determination of copper, nickel and cadmium by FAAS after preconcentration with zinc-piperazinedithiocarbamate loaded on activated carbon by solid-phase extraction, Anal. Lett. 33 (2000) 1991-2004.

[100] Y. Madrid, C. Cámara, Biological substrates for metal preconcentration and speciation, Trends Anal. Chem. 16 (1997) 36-44.

[101] E. Beceiro-González, A.T. Calzada, E. Alonso-Rodriguez, P. LópezMahía, S. Muniategui-Lorenzo, D. Prada-Rodríguez, Interaction between metallic species and biological substrates: approximation to possible interaction mechanisms between the alga Chlorella vulgaris and arsenic(III), Trends Anal. Chem. 19 (2000) 475-480.

[102] S.L. Bailey, T.J. Olin, R.M. Bricka, D.D. Adrian, A review of potentially low-cost sorbents for heavy metals, Water Res. 33 (1999) 2469-2479.

[103] M.G. Pereira, M.A.Z. Arruda, Preconcentration of Cd(II) and Pb(II) using humic substances and flow systems coupled to flame atomic absorption spectrometry, Microchim. Acta 146 (2004) 215-222.
[104] C.R.T. Tarley, S.L.C. Ferreira, M.A.Z. Arruda, Use of modified rice husks as a natural solid adsorbent: characterization and development of an online preconcentration system for cadmium and lead determination by FAAS, Microchem. J. 77 (2004) 163-175.

[105] H. Bag, M. Lale, A.R. Türker, Determination of $\mathrm{Cu}, \mathrm{Zn}$ and $\mathrm{Cd}$ in water by FAAS after preconcentration by baker's yeast (Saccharomyces cerevisiae) immobilized on sepiolite, Fresenius J. Anal. Chem. 363 (1999) 224230.

[106] H. Bag, A.R. Türker, M. Lale, Determination of $\mathrm{Cu}, \mathrm{Zn}, \mathrm{Fe}, \mathrm{Ni}$ and Cd by flame atomic absorption spectrophotometry after preconcentration by Escherichia coli immobilized on sepiolite, Talanta 51 (2000) 10351043.

[107] A. Maquieira, H. Elmahadi, R. Puchades, Use of S. cerevisiae in flow injection atomic absorption spectrometry for thace metal preconcentration, Anal. Chem. 66 (1994) 1462-1467. 